\title{
QUÉ PIENSA DE LA PUBLICIDAD Y DE SUS TÉCNICAS LA COMUNIDAD DE LATINOS INMIGRANTES EN ESPAÑA
}

\author{
Álvarez Ruiz, Antón \\ Facultad de CC. de la Información \\ Universidad Complutense de Madrid \\ antón.alv@gmail.com \\ antonalv@pdi.ucm.es
}

Material original autorizado para su primera publicación en la revista académica REDMARKA, Revista Digital de Marketing Aplicado.

https://doi.org/10.17979/redma.2009.01.03.4689

\section{Antón Álvarez Ruiz}

Profesor Titular interino de la Facultad de CC. de la Información de la Universidad Complutense de Madrid, en la asignatura "Sistemas y Procesos de la Publicidad y las RRPP. Estrategias de Comunicación". Doctor en Publicidad e investigador especializado en los efectos sociales de los medios de comunicación y la medición del cambio social, temas sobre los que ha publicado libros y artículos e impartido Másters y conferencias. Planner publicitario free-lance al servicio de agencias de publicidad y empresas anunciantes. Miembro de la APG-Account Planning Group, principal asociación mundial de planners estratégicos.

(Ver:http://www.ucm.es/centros/webs/d167/index.php?tp=Profesorado\&a=comunes\&d=listaprof s.php\&centro=167) 


\title{
Resumen
}

Este artículo expone los resultados de varios grupos de discusión (focus groups) realizados recientemente con inmigrantes de diversos países de Latinoamérica residentes en España. En dichos grupos se investigó a través de la metodología cualitativa empleada habitualmente en los grupos de discusión, qué opinión tienen sobre la publicidad que presencian en nuestro país, tanto a nivel general como entrando en detalles sobre tipos de anuncios, retóricas (estilos) publicitarias y marcas. También se investigó a fondo sobre cómo veían el papel de los personajes latinos que aparecen en la publicidad española tipologías, acentos lingüísticos, roles desempeñados, etc.- y su grado de identificación con ellos.

El artículo explicar el amplio muestrario de efectos observado en los inmigrantes y su rápida adaptación al tipo de publicidad realizada en España, bastante diferente a la de sus países de origen.

Los datos de este artículo fueron obtenidos en el curso de un Proyecto de Investigación Art. 83 LOU, realizado para la Asociación de Agencias de Publicidad española por la Universidad de Villanueva y la Universidad Complutense de Madrid.

\section{Palabras clave:}

Publicidad e inmigración. Marketing e inmigración. Inmigración en España.

\begin{abstract}
Abstrac:
WHAT DOES THE LATIN INMIGRANT COMMUNITY THINK ABOUT PUBLICITY AND ITS TECHNIQUES IN SPAIN
\end{abstract}

This article explains the results of various focus groups done recently with inmigrants from Latine America living in Spain. With the qualitative methodology that is generally used in the focus groups, we have investigated what is their 
opinion about advertising in our country in general, but also getting into some detail with the type of advertisement, the styles of communication and the brands being advertised. It was also thoroughly investigated the perception they had of the part played by the latin characters that appear in the spanish advertisement -typology, verbal pronunciation, role played, etc.- and how they identify with them.

The article tries to explain the wide range of effects observed on the inmigrants and how they quickly get used to the Spanish advertisement, which are quite different to the one they see in their countries.

The data used for this article was obtained during an investigation done for Asociación de Agencias de Publicidad española (Spanish Advertising Agencies Asociation) by Universidad de Villanueva and Universidad Complutense de Madrid, Spain.

\section{Key words:}

Advertising and inmigration. Marketing and inmigration. Inmigration in Spain. 
Este artículo ha sido escrito explotando los datos obtenidos para la realización de un Proyecto de Investigación -Artículo 83 LOU- realizado en 2008 para la Asociación Española de Agencias de Publicidad (AEAP) de España por un equipo de investigación de la Universidad de Villanueva y de la Universidad Complutense de Madrid, compuesto por Belén López Vázquez, Ana Sebastián Morillas y Nuria Villagra. Este equipo estuvo dirigido por Sonia Carcelén García y el autor del presente artículo.

\section{1.- EL INTERÉS DEL PÚBLICO INMIGRANTE PARA EL "MARKETING" Y LA PUBLICIDAD}

Nadie duda que la llegada masiva de inmigrantes a España constituye uno de los fenómenos sociales más notorios de la historia reciente de nuestro país. En la actualidad hay alrededor de 5,2 millones de inmigrantes ${ }^{(1)} y$, a pesar de las fluctuaciones de la evolución económica, se espera que su número ascenderá a los 8 millones en el año 2015. Para el año 2025, contando con el incremento por la tasa de natalidad, se calcula que 3 de cada 10 habitantes de nuestro país no hayan nacido en España o sean hijos de padres extranjeros ${ }^{(2)}$.

$\mathrm{Y}$ dentro de todo el colectivo de inmigrantes, es muy significativo el de aquellos que han venido de los países centroamericanos y del norte de Sudamérica, especialmente de Ecuador, Colombia, Bolivia y Perú, países que, por este orden, constituyen el origen del principal flujo de inmigrantes latinos y que han aportado casi un millón de habitantes a nuestro país ${ }^{(3)}$. En total, la inmigración latina constituye la comunidad étnica inmigrante más numerosa en España y supone el $36 \%$ del total de inmigrantes.

Por su parte, la industria publicitaria y el marketing están siempre muy atentos a los cambios sociales y a la aparición de nuevos nichos de públicos a los que dirigir sus mensajes y sus productos. A este respecto, y según datos Nielsen de 2007 , el colectivo inmigrante supone ya el $10 \%$ del consumo total de nuestro 
país, con un gasto per cápita mensual de $1.081 €$ en productos de gran consumo. Además, una gran cantidad de emisores públicos -especialmente el Gobierno Central, los gobiernos autonómicos y los municipios- y un buen número de compañías y corporaciones realizan importantes inversiones ${ }^{(4)}$ en campañas sociales sobre la problemática de los inmigrantes, algunas de ellas destinadas específicamente a los inmigración latina.

Todas estas cuestiones parecen indicar la necesidad de estudiar cómo el público inmigrante percibe y valora la publicidad que recibe en España y cómo reacciona ante ella, para saber si la publicidad y el marketing están actuando adecuadamente ante esta nueva realidad.

Además, como los consumidores españoles comparten el mismo idioma y un buen número de características culturales con el colectivo de inmigrantes latinos, sin duda resulta más fácil estudiar a este colectivo que a otras etnias inmigrantes que guardan una mayor disimilaridad con el público de nuestro país.

Por ello, se ha realizado el presente estudio de perfil sustancialmente cualitativo, el primero de sus características realizado en nuestro país, encargado por la Asociación de Agencias de Publicidad-AEAP, que ha tratado de conseguir una visión completa y que pudiera integrar a los pocos estudios cuantitativos realizados sobre el colectivo inmigrante, y también servir de referencia a las investigaciones que quizás se aborden desde ahora sobre este tema.

Para el presente artículo nos hemos centrado en una de los grandes áreas del estudio: qué piensan los inmigrantes latinos de las campañas publicitarias y del personaje latino cuando aparece reflejado en las mismas.

\section{2.- METODOLOGÍA DE LOS GRUPOS DE DISCUSIÓN}


Para la obtención de estos datos se realizaron ocho grupos de discusión que, por el grado de coherencia en las respuestas, han constituido una base bastante solvente para fundamentar la investigación. La metodología general de los grupos ha seguido los criterios habituales en esta modalidad de investigación cualitativa, tanto en su filosofía(5) como en sus aspectos concretos $^{(6)}$. Adicionalmente, hemos aplicado algunos criterios metodológicos específicos para la selección de los asistentes y el desarrollo de los grupos que explicamos en los puntos siguientes.

\section{Elección de la muestra}

Los miembros participantes en los grupos sufrieron un proceso muy riguroso de selección para tratar de emular con precisión al colectivo de emigrantes latinos residente en España, siendo segmentados preferentemente por tres variables sociodemográficas:

- Edad: se discriminaron dos franjas de edad, de 16 a 23 años y de 24 a 38 años, para separar a los jóvenes de los más adultos, que sabíamos suelen mostrar una aproximación bastante diferente a las pautas de consumos y a las marcas ${ }^{(7)}$. Se eliminaron conscientemente a los mayores de 38 años y a los menores de 16 por resultar poco significativos para este trabajo.

- Sexo: se realizaron grupos de hombres y de mujeres por separado respetando las otras variables establecidas de edad, tiempo de estancia, representatividad del país...- pues sabemos que las mujeres de este colectivo tienden a no mostrarse en público abiertamente en desacuerdo con los varones, por lo que podrían inhibir sus respuestas. La separación por sexos no pareció afectar en ninguna dirección a los varones, pero permitió que las mujeres expresaran sus ideas con mayor libertad y detalle. 
- Tiempo de estancia en nuestro país: hemos discriminado dos grandes franjas: una entre 1 y 3 años y otra entre 4 y 8 años. Así, hemos descartado a los que acababan de llegar y no tenían una imagen asentada de la situación y a los que, por llevar más de 8 años, muestran ya una elevada asimilación con las opiniones de los ciudadanos españoles.

En cada grupo se reunió a unas siete $u$ ocho personas que representaron las diferentes nacionalidades latinas que han dominado la incorporación inmigratoria procedente de América a nuestro país pero, en cambio, no hemos tenido en cuenta a los países latinoamericanos de mayor renta per cápita y que tienen un historial más largo de emigración a nuestro país (Argentina, Chile, Méjico...) porque su problemática es muy diferente y podría incorporar importantes interferencias.

En concreto, los grupos de dividieron así:

\begin{tabular}{|c|c|c|c|}
\hline & Sexo & Edad* & $\begin{array}{l}\text { Tiempo de } \\
\text { residencia* }\end{array}$ \\
\hline Grupo $n^{0} 1$ : & Hombres & 16 a 23 & 1 a 3 \\
\hline Grupo $n^{\circ} 2:$ & Hombres & 24 a 38 & 1 a 3 \\
\hline Grupo $n^{\circ} 3$ : & Mujeres & 16 a 23 & 1 a 3 \\
\hline Grupo $n^{\circ} 4:$ & Mujeres & 24 a 38 & 1 a 3 \\
\hline Grupo $n^{\circ} 5:$ & Hombres & 16 a 23 & 4 a 8 \\
\hline Grupo $n^{\circ} 6:$ & Hombres & 24 a 38 & 4 a 8 \\
\hline Grupo $n^{\circ} 7$ : & Mujeres & 16 a 23 & 4 a 8 \\
\hline $\begin{array}{l}\text { Grupo nº } 8: \\
\left(^{\star}\right) \text { En años }\end{array}$ & Mujeres & 24 a 38 & 4 a 8 \\
\hline
\end{tabular}

Los grupos se realizaron en Madrid durante el mes de junio de 2008, en los locales de Merka Star, empresa especializada en focus groups y otras técnicas 
cualitativas que fue quien realizó la selección de los asistentes, siguiendo los criterios fijados por los investigadores.

\section{Desarrollo de los grupos}

Los grupos siguieron todos ellos un guión parecido, establecido de antemano, aunque en algunos de ellos se varió levemente, siguiendo los criterios de flexibilidad con los asistentes habituales en estos casos:

1) El moderador del grupo se presentaba y realizaba una breve introducción al tema.

2) Los asistentes del grupo se presentaban a sí mismos (nombre de pila, tiempo de estancia en España, situación personal y profesional y algún otro comentario general).

3) Se iniciaba una discusión abierta, en la que el moderador conducía el curso de la discusión para ahondar en las situación comentadas. Cuando consideraba que un aspecto estaba agotado, introducía el siguiente.

4) Posteriormente se proyectaban en un televisor cuatro o cinco campañas publicitarias y tras cada proyección se iniciaba un debate sobre ellas.

La duración de los grupos osciló entre 120 y 150 minutos. Las reuniones fueron grabadas en audio y vídeo con el permiso expreso de los asistentes y las grabaciones transcritas para tratar, contrastar y estructurar la información obtenida. Es de destacar que se ha obtenido un cierto nivel de redundancia (repetición de las mismas opiniones en grupos diferentes) lo que refuerza la veracidad y solvencia de las informaciones obtenidas. 


\section{3.- CÓMO PERCIBE LA PUBLICIDAD EL INMIGRANTE LATINO}

Lo primero que se constata al abordar este tema es que los inmigrantes latinos están acostumbrados a ver en sus países de origen una publicidad muy diferente a la que presencian en España. Y ello, por dos grandes aspectos. El primero es cuantitativo: en su países no están acostumbrados a soportar un nivel tan elevado de saturación publicitaria, especialmente en televisión. Es algo que perciben de forma instantánea y les llama la atención ${ }^{(8)}$ :

"Lo que pasa es que, por ejemplo, cuando estás viendo la televisión, y estás viendo una peli, o sea, los anuncios duran casi media hora. Y ya llega un momento en que... o sea, no los ves." (Grupo no 5 )

Podemos añadir que esta elevada presión publicitaria no es sólo consecuencia de la gran cantidad de anuncios que ven en los medios convencionales sino también por la existencia de nuevos y numerosos canales, soportes y espacios de anunciar que incrementan esa percepción de saturación.

El segundo aspecto es de tipo cualitativo, pues los códigos de comunicación y el estilo de la publicidad española les resulta sutil y sofisticado, muy alejado de las propuestas directas existentes en sus países. El descubrimiento de estos códigos les produce en un principio sorpresa y desconcierto y comprenderlos les lleva algún tiempo. También ven las campañas españolas con mayor altura estética, mejor terminadas y con una mayor intención comunicativa. En otros casos, se destaca el nivel de espectacularidad que tienen las campañas.

Todos estos aspectos resultan lógicos. Por una parte, el nivel de retorización de la publicidad española es muy elevado; los mensajes tienen una mayor elaboración, buscan la venta siguiendo caminos menos obvios. Y, por otra parte, el presupuesto de producción es bastante más elevado en nuestro país, basando incluso algunas campañas su notoriedad en este único aspecto. 
También destacan los inmigrantes latinos que los productos y servicios anunciados parecen resultar más lujosos o detentadores de un estatus más elevado.

“- Aquí (en España) por ejemplo, promocionan cosas más caras. Allá en general no pueden hacer eso porque la gente no tiene tanto presupuesto para comprarse las cosas. Aquí promocionan trajes de baño, o Calvin Klein... Allí (...) lo normal es que te promocionen refrescos, algunas tiendas, centros comerciales, $y$ tal, pero no te promocionan nada de productos así.

- MODERADOR: O sea, que tú notas que los productos que se anuncian son de más lujo, de más...

- Y, sí. Generalmente sí." (Grupo nº 5)

Podemos atribuir este hecho a dos situaciones: por una parte nuestra publicidad tiene un grado más elevado de glamourización; por otra, nuestro nivel de consumo permite que también los productos de elevado precio lleguen a los grandes medios de comunicación, cuando en los países latinos sólo aparecen en medios muy selectivos, como las revistas de élite.

Hay otro elemento que les llama la atención inmediatamente y es el elevado porcentaje de anuncios de tipo institucional presentes en nuestro país. No están acostumbrados a ver campañas de la Administración Central, autonomías, ayuntamientos, o fundaciones, ni tampoco campañas de empresas privadas que se ocupen de un fin social (ahorro de energía, respeto al medio ambiente, etc.). En sus países de origen, la publicidad se dedica casi siempre a productos comerciales e incluso los servicios parecen tener una presencia muy limitada. Por este motivo, los inmigrantes muestran una leve confusión inicial ante las campañas sociales ("¿qué quieren venderme con esto?") que desaparece rápidamente a medida que se acostumbran a esta nueva situación. 
También podemos destacar un cierto sentimiento de engaño ante algunas campañas publicitarias, especialmente aquellas que presenta promociones o descuentos.

“- Ellos (se refiere a las compañías operadoras de telefonía) mienten mucho.

MODERADOR: ¿Mienten mucho?

- Sí...

MODERADOR: Pero, ¿en qué sentido?

- (...)Porque ellos te dicen "cambia el contrato porque, con nosotros, durante un mes te va a costar $38 € \ldots$ no, 25", te dicen. Y tú dices, "pago 25 y ya está, ¿no?" Y me dice 25, pero después de esta cantidad está el 16\% de IVA, el 16\% de otras cosas (...) Terminas pagando $50 € \ldots . "\left(G r u p o n^{\circ} 5\right)$

Los inmigrantes parecen leer los mensajes publicitarios de una forma mucho más literal que el público español. Esto quizás explique el nivel de crítica que suscitan, por ejemplo las campañas de las operadoras de móviles. El hecho es que se sienten relativamente estafados por la publicidad de las tarifas y porque éstas destacan una ventaja -la más señalada- que les lleva al engaño o a la confusión, por la existencia de otras condiciones en letra pequeña. Este fenómeno de "leer la publicidad de una forma muy literal" parece darse en todo tipo de públicos entre los latinos inmigrantes, desde los más jóvenes a los de mayor edad:

“- Te dicen "i20 Megas!", te dicen... Y yo he estado con los técnicos (...) de Telefónica (...) Me los encuentro en la calle y me dicen: "mira, 20 Megas no le llegan a nadie. Lo que llegará a tu casa son unos 6 megas". Pero ellos (se refiere a las campañas de publicidad de Telefónica) hablan de la máxima velocidad y entonces te dicen "eso es imposible"...

- Y dicen "hasta 20 Megas", pero claro... te dicen "hasta".

(Grupo $n^{\circ} 5$ ) 
Sin duda, por el tipo de publicidad existente en sus países de origen, a los inmigrantes latinos les falta la experiencia necesaria para captar estas argucias semánticas. Pero también parecen deberse a cuestiones idiomáticas, como un manejo del idioma menos fluido. $Y$, en ciertos casos, al menor nivel de instrucción cultural de algunos colectivos de inmigrantes.

\section{Los aspectos más valorados de la publicidad}

De entrada, los inmigrantes latinos mantienen que no les gusta la publicidad como hecho comercial y afirman que la publicidad tendría que ser puramente descriptiva e informativa. En realidad, este es un comentario que surge en casi todas las encuestas generales sobre la industria publicitaria realizadas en cualquier país desarrollado y con cualquier colectivo, y contiene importantes elementos de ámbito ideológico -como el rechazo proyectado hacia la sociedad de consumo- que se ven acrecentados en situaciones de escasez económica:

"La publicidad que no nos gusta es la que nos hace crear ilusiones y luego cuando vas a la tienda a ver, encuentras otra cosa" (Grupo n 4$)$

Pero inmediatamente después de esta crítica, destacan la calidad de la publicidad española:

"Todas las marcas hacen su publicidad tratando de llegar a nosotros, para que nosotros la compremos. Entonces es muy difícil encontrar un comercial malo" (Grupo n 4 )

Los inmigrantes latinos admiten que les gustan ciertas campañas de publicidad. Así, dicen disfrutar de los anuncios que están bien producidos, los que incorporan el humor o les proponen una interpretación inteligente y los que utilizan famosos. Pero debemos destacar que, aunque estos recursos despiertan la atencionalidad y el recuerdo de los anuncios concretos, no 
garantizan el recuerdo de las marcas anunciadas. También resulta evidente que la presencia de caracteres latinos -0 , por extensión, de personajes que reflejen variedad étnica- incrementa el interés de las campañas $y$, posiblemente, su nivel de credibilidad. Pero vamos a estudiar todos estos efectos con más detalle.

\section{La utilidad de la publicidad inteligente, el humor y los famosos}

Como ocurre con el público español, a los inmigrantes latinos les aburren las campañas tópicas con final previsible y les atraen aquellas que aportan ideas innovadores. Por eso destacan que, en primer lugar, lo que más les atrae de un anuncio es la creatividad, la novedad de la idea o del enfoque de la campaña, aspecto que les merece sentimientos de admiración:

“- Es que ¡cómo lo hacen! Son muy imaginativos en ese sentido (los publicitarios)..." (Grupo $\left.n^{\circ} 5\right)$

- Es la imaginación (lo que llama la atención en un anuncio), es decir, que se ponga, qué se yo, lo del Pancho (se refiere a la campaña vigente de Lotería Primitiva, en la que un perro le roba a su dueño un billete de lotería premiado y lo disfruta por él). ¿Quién se va a poner a pensar que un perro va a hacer eso? Y te llama la atención." (Grupo n 5)

También aceptan de muy buen grado las campañas que utilizan el humor en cualquiera de sus variantes, como los chistes originales, las situaciones cómicas, el absurdo, la ironía, la exageración, un final inesperado...

"Es que es eso lo que trata de hacer la publicidad: que te divierta, que te... que (las campañas) sean llamativas para ti" (Grupo $\left.n^{0} 1\right)$

"Hay algunas tonterías que no entiendes algunas veces, pero la mayoría (de las campañas) también son divertidas" 
(Grupo n 1)

Y parece que el humor gusta porque además les transmite un estado de ánimo positivo. De la misma manera, también despiertan la atención y el recuerdo las campañas que recurren al ingenio, desafiando la inteligencia del espectador; a los inmigrantes latinos les gusta jugar a desentrañar el mensaje:

"La sorpresa... Hay una (campaña) muy divertida (en la) que está un chico con una chica... Y es un chicle, una marca de chicle. Y la besa y aparece el chicle..." (Grupo $\left.n^{\circ} 1\right)$

“...Y sorprendente, porque tiene que sorprenderte para que veas el producto..." (Grupo no 1)

Pero si este juego de acertijos no llega a buen fin, se sienten decepcionados y la sensación negativa suele transmitirse a la marca anunciada.

Un elemento relacionado con los anteriores que les gusta especialmente a los jóvenes, es la existencia de cierta interactividad en las campañas que estimule la respuesta del público o que, en su defecto, la simule. Ello hace que el público se siente partícipe o incluso protagonista de la propuesta publicitaria, ya sea de forma real o figurada. Por ejemplo, en varios grupos se mencionó de forma espontánea la campaña "Lola" de Coca-Cola, entonces en el aire. Como es sabido, esta campaña utilizaba el conocida tema del grupo inglés The Kinks y solicitaba la participación de los consumidores para que enviasen filmaciones caseras tipo "You Tube" que pudieran ser emitidas como anuncios de dicha campaña:

“- MODERADOR: ¿Por qué os llama la atención ese anuncio de "Lola"? ¿Por algo en concreto?

- Porque es algo interesante, innovador, bien hecho... de que la gente sola, por sus medios, con un poco de educación puede, pues eso, subir más. Es interesante" (Grupo n 5 ) 
También les impactn los anuncios con un notable nivel de producción o de postproducción, o los que busquen el entretenimiento desde el espectáculo. Por ejemplo, mencionan con entusiasmo la campaña "Transformers" de Citröen, en el aire en ese momento (un anuncio de televisión que integraba animación en 3-D, imagen real y postproducción, y que mostraba a un coche que se desplegaba sobre sí mismo, conformando un gigantesco robot).

Aunque en menor medida, también aparecen como atencionales otros recursos más tópicos y sobreutilizados por la industria publicitaria como mostrar a una mujer seductora:

"La mujer vende" (Grupo no 1)

"En el plano, pues ves a una chica con una sonrisa y la sonrisa se te queda, y ya... l lo que ponga! Pero la sonrisa de la chica a uno se le queda" (Grupo n 1 )

O mostrar niños para apelar al sentimiento:

"Cuando los niños aparecen en un anuncio, siempre da gracia. Y sí, vende" (Grupo n⿳1)

A este respecto, también mencionan de forma espontánea la entonces vigente campaña de imagen de Endesa, que mostraba niños que deseaban cambiar el futuro del mundo (ver anuncio $n^{0} 1$ ). 




Anuncio $n^{\circ}$ 1. Campaña institucional de Endesa emitida en el 2008 y mencionada en los focus groups como un ejemplo positivo de la utilización de la figura infantil.

Otro recurso que demuestra su elevada capacidad para atraer la atención del público inmigrante latino es el empleo de personajes famosos, especialmente deportistas:

“- Por ejemplo, la publicidad de la Coca-Cola es muy chévere, muy... Utiliza famosos...

- Utiliza a muchos famosos, deportistas, y eso llama mucho la atención" (Grupo n 1)

Los inmigrantes más jovenes le restan importancia a este efecto, quizás para no sentirse manipulados, y creen que si visten ropa de las marcas deportivas de moda lo hacen más por "vestir la camiseta que patrocina a su equipo o a su deportista favorito" -esto es, en términos de comunicación, que el consumidor establezca una forma de equiparación semiótica con el equipo o el ídolo admirado- más que por el efecto de la "publicidad de famosos" en sí. 
"- A lo mejor el del Barcelona lleva Nike, y el Madrid lleva Adidas. Y si eres del Barcelona, llevas Nike. Porque es del Barcelona, no porque haya estado Ronaldinho (...)

- Y hay mucha gente (a la) que le encanta Ronaldinho y lleva Adidas. Roberto Carlos lleva Adidas, pues yo me visto Adidas" (Grupo $\left.n^{\circ} 5\right)$

Lo que resulta indudable es que utilizar famosos o personalidades le suele dar a las acciones publicitarias muy buenos resultados en cuanto a notoriedad en todas las franjas de edad del público inmigrante latino, incluso entre los jóvenes y más críticos, porque todos los encuestados recuerdan y mencionan de forma espontánea este tipo de anuncios. Quizás, además, opere aquí un factor de afinidad que establecen algunos famosos deportistas, particularmente del mundo del fútbol: muchos de ellos son también inmigrantes latinos en España. Y su éxito les permite, simultáneamente, una identificación con ellos como personas pero también una proyección hacia el personaje social que representan y las marcas que visten o anuncian.

Pero también resulta evidente que todos estos recursos retóricos y estilísticos mencionados anteriormente -el uso de la creatividad, la intención, el humor, los sentimientos, la presencia de famosos...- incrementan la atencionalidad y hacen que se dispare la notoriedad, con lo cual los anuncios respectivos logran el recuerdo del público. Pero, en bastantes ocasiones y aunque se recuerde perfectamente el anuncio, el público latino no es capaz de mencionar las marcas anunciadas.

Como vemos, se produce aquí un problema de pertinencia: si resulta útil utilizar una determinada figura retórica o un determinado famoso porque están perfectamente alineadas con la personalidad de la marca o el producto, o si son un simple artificio añadido. No obstante, la recordación de los anuncios que no remite a las marcas es un problema absolutamente habitual en casi todas las encuestas de post-test realizadas sobre cualquier tipo de público y está muy relacionado con la saturación de los mensajes publicitarios. Pero en nuestra investigación hemos podido comprobar que tiene un valor significativo 
por el número de veces que lo hemos detectado. Quizás ciertas incomprensiones culturales o idiomáticas, refuercen este problema en el caso de los inmigrantes latinos.

\section{La presencia de caracteres étnicos}

Por último, un recurso que es altamente valorado en las campañas publicitarias por todo el colectivo inmigrante latino, sin distinción de sexo o edad, y que ellos mismos comentan con profusión es el hecho de verse reflejados en la propia publicidad, a través de la presencia de personajes latinos en concreto o extranjeros en general.

“Ellos ponen personas (latinas en las campañas) (...) Nos los muestran bailando, bebiendo, los muestran haciendo una actividad, mostrando que son parecidos a nosotros, incluso que tengan algún rasgo latino, o... Eso a mi me gusta..."

(Grupo $\left.n^{0} 1\right)$

“Claro: nos sentimos identificados..." (Grupo n 1)

Además de garantizar la atencionalidad y la identificación con estas campañas, la presencia de personajes latinos les recompensa y gratifica, pues inconscientemente es una apelación a la igualdad entre razas. Los inmigrantes latinos destacan espontáneamente algunas campañas generalistas dirigidas a todos los públicos donde aparecen caracteres latinos, en temas sociales como las campañas de integración realizadas por la Comunidad de Madrid (ver anuncio $\left.n^{\circ} 2\right)$ :

"No, también la Comunidad de Madrid vende... Vende 'productos' así como para integración..." (Grupo nº 1) 




Anuncio $n^{\circ}$ 2. Campaña de la Comunidad de Madrid para la integración, en el que personas de diferentes razas hacen equipo para pintar la bandera de la Comunidad.

Este efecto aparece también en las campañas de productos comerciales como las de Carrefour y otros centros comerciales generalistas:

"Ahora sí, porque en Carrefour, aquí, en Madrid... latinos hay muchos. $Y$ hay tiendas que sólo... Hay un sector así latino (se refiere a los espacios exclusivos de alimentos latinos existentes en ese centro comercial). $Y$, todo (es) latino, de Sudamérica, Centroamérica, todo esto..." (Grupo $n^{0} 1$ )

“...Se dan cuenta de que hay mucha gente de ese país y se dan cuenta de que ese es un... un hueco que hay que cubrir, claro..." (Grupo $\mathrm{n}^{\circ}$ 1) 
Por extensión, les llaman la atención no sólo los personajes latinos, también todos los elementos que les referencian a su país: noticias e informaciones, carteles de conciertos con cantantes propios, viajes a sus países de origen, su bandera nacional a la entrada de un hotel, etc.:

"Porque si ves algo del país, te interesa muchísimo"

(Grupo $n^{\circ}$ 1)

"Los carteles que colocan en los conciertos de gente que viene para acá del país, que aquí no son conocidos,... conocidos pero que... con su gente... a mi me llaman mucho la atención" (Grupo $n^{\circ} 1$ )

"Para mi,... yo dije 'alegría'. Porque cuando, por ejemplo, ves una publicidad que vende un viaje a tu país barato: alegría..." (Grupo $n^{\circ}$ 1)

Sin embargo, no recuerdan de forma espontánea demasiadas campañas en las que aparezcan personajes latinos y se dirijan a ellos. En este sentido llama la atención que citen con frecuencia un anuncio de Movistar específico para el público latino ("No me cuesta"), anunciando tarifas más económicas para hablar con el país de origen:

"Una compañía grande que era de estas..., por ejemplo, Movistar,... de "llama a tu país" o algo así. Y que eran personas latinas, que ponían en el anuncio. Yo no sé cuantificarlo, pero se les notaba claramente que eran latinos." (Grupo no 1 )

"Latinos, sí, y que salían en el anuncio y decían: 'oh, yo quiero hablar con fulanito'. Se les identificaba, sabías que tú estabas en la misma situación que esa persona, no sé... Te alegras, por una parte, aunque es un poco melancólica, pero también te identificas con eso" (Grupo no 1) 
Pero, aunque el recuerdo espontáneo de las campañas con personajes latinos es relativamente bajo -algo que ocurre con casi todas las campañas analizadas en esta investigación, si exceptuamos las de telefonía y algunas otras-, posteriormente, al ver varios anuncios que incorporaban personajes latinos, ya mostraban recordarlos con claridad; por lo que el recuerdo sugerido es bastante elevado y demuestra que estas campañas están latentes en su memoria.

Por los efectos estudiados pensamos que, aunque los inmigrantes latinos proclaman abiertamente que les gusta ver personajes latinos en la publicidad, esto debe interpretarse como una búsqueda indirecta de protagonismo, reconocimiento e igualdad social. $Y$ aunque este recurso parece garantizar la notoriedad y la identificación las campañas, es un tema que debe manejarse con delicadeza a la hora de desarrollar campañas publicitarias.

Por extensión, les llaman notablemente la atención las campañas multiculturales y aquellas en las que se refleja la variedad étnica. Este tipo de campañas parece ser un referente para ellos porque parecen promover valores de igualdad entre personas de diferentes colectivos raciales:

“- A mí el (anuncio) de Endesa me gusta mucho, el de los niños estos que...

- MODERADOR: Pero, ¿por lo que dice, o por cómo está hecho?

- Yo creo que por la forma en que integra a todos los grupos, ¿sabes? O sea, que nadie se distingue por nada (ninguna etnia se impone sobre las otras)..." (Grupo $n^{\circ} 5$ )

En efecto, todo tipo de campaña en medios generalistas que muestre la diversidad cultural, étnica, religiosa, etc. les resulta muy gratificante. $Y$ ello ocurre por varios motivos: porque se sienten parte de un colectivo universal más que como una minoría en un país extranjero; porque perciben que estas campañas transmiten y propagan modelos integracionistas que superan las 
diferencias raciales desde una concepción muy amplia; porque se sienten respaldados en su búsqueda diaria de una igualdad real...

\section{4.- CUANDO EL INMIGRANTE LATINO ASUME EL PROTAGONISMO EN LAS CAMPAÑAS DE PUBLICIDAD}

Analizaremos ahora qué piensan y sienten los inmigrantes latinos cuando se ven reflejados en la publicidad. En este tema podemos distinguir dos grandes apartados:

- La presencia de caracteres latinos en campañas dirigidas a todos los consumidores en general.

- La presencia de caracteres latinos en campañas dirigidas solamente al inmigrante latino y que suelen aparecer en medios de comunicación exclusivos para este público.

Por cuestiones de espacio, sólo abordaremos en este artículo el primero de estos dos puntos, que resulta socialmente el más interesante. Adelantamos que algunas de las opiniones recogidas y observadas pueden parecer contradictorias. Pero, dado que proceden de grupos de públicos perfectamente seleccionados y contrastados con otros grupos similares, debemos atender estas opiniones como veraces y significativas. Lo que ocurre es que, con frecuencia, y dado que se están tratando temas en los que las personas muestran un elevado grado de implicación personal, la realidad y las situaciones proyectadas se entremezclan. Pero es nuestro trabajo analizar todas estas cuestiones, tratando de distinguirlas unas de las otras y valorarlas debidamente.

\section{La aparición del personaje latino}


Correspondiéndose con lo que ocurre en la realidad social, los inmigrantes latinos detectan una progresiva presencia en las campañas de publicidad de personajes y caracteres similares a ellos. No sólo identifican personajes latinos, también de otros tipos de etnias -asiáticos, árabes o de raza negra- aunque han podido comprobar que la presencia de latinos es muy superior a las demás.

Tal y como hemos comprobado que sucede, los inmigrantes iberoamericanos entrevistados detectan que los primeros personajes latinoamericanos aparecidos en las campañas de publicidad son celebridades, especialmente deportistas.

También observan que el proceso apenas acaba de comenzar y que esta presencia crece cada día. Y la relacionan directamente no con el número real de inmigrantes latinos sino con el incremento de su nivel de visibilidad en la calle, en las empresas y, en general, en la vida social española.

“- El público sudamericano se está viendo aquí,... un poco... muy despacito.

- MODERADOR: Muy despacito.

- Pero ahora hay mucho, mucho, mucho (...)

- Sí, lo de la publicidad será cuestión de unos años y poquito más que empiecen a... que empiecen a salir." (Grupo $n^{\circ} 5$ )

De esta forma, piensan que su presencia pública en la vida activa es lo que les ha hecho merecer un papel significado en las campañas de publicidad. Y, para ellos, este hecho supone un importante reconocimiento y un motivo de alegría y orgullo:

"Por lo menos tú sientes que nos toman en cuenta. Uno dice:

'¡Hombre!, ya era hora de que saliera un latino'. Como normalmente no salen... Entonces lo ves ahí y dices: 'iguau!" (Grupo $\left.n^{\circ} 4\right)$ 
"No importa del país que se sea, pero con tal de que sean latinos ya es un orgullo para uno." (Grupo $\mathrm{n}^{\circ} 4$ )

Se sienten bien cuando aparecen personajes latinos, pero no sólo en la publicidad, también cuando sucede en los telediarios, concursos..., es decir, cuando ocupan un papel protagonista en los medios de comunicación o en la vida pública y cuando son representados integrados interactuando junto a personas no inmigrantes. Creen que es una manera de reflejar una realidad social que existe: ya que cada vez hay un mayor número de inmigrantes en España, merecen un protagonismo correspondiente dentro de los diferentes contenidos temáticos de los medios de comunicación.

Sin duda, la presencia de latinos en los medios representa para ellos la proyección deseada de una situación ideal -la plena equiparación social, económica y cívica- y simultáneamente, constituye un modelo o referente que emite pautas integracionistas que sienten que son muy eficaces a nivel social, aunque estos aspectos no se expresen de forma consciente en las entrevistas realizadas. Por estos dos motivos, los inmigrantes se sienten identificados con las imágenes y valores transmitidos por los personajes latinos mostrados en las campañas publicitarias:

“- MODERADOR: ¿Y vosotros os sentís cómodos con la imagen que da de lo latino este tipo de campañas?

- Sí.

- Sí, sí. Yo creo que ayuda." (Grupo n 5)

Pero al inmigrante latino les gusta preferentemente aparecer como tal latino y no como parte de los demás colectivos que han emigrado a España, pues aprecian marcadas diferencias entre las distintas etnias inmigrantes -por su procedencia y por su problemática particular- y donde ellos reconocen ocupar un papel menos desfavorecido que otros: 
"- Pero ya no hablamos de los latinos, hablamos de los africanos, de esos que entran en cayuco. Ahora mismo, ¿les han visto hacer algún anuncio en la televisión?" (Grupo nº 5)

Entrando en detalles, se sienten un poco incómodos cuando los medios tratan a todos los latinos como un colectivo homogéneo, sin diferenciaciones culturales, idiomáticas, etc.:

“Tratar por igual a todos no me gusta. Eso de 'la gente latina' no me gusta, porque somos latinos pero, dentro de eso, somos muy diferentes." (Grupo $\left.n^{\circ} 4\right)$

"Los bolivianos, con los ecuatorianos y hondureños..., nada que ver, desde la comida hasta la forma de vestir y las costumbres." (Grupo $\left.n^{\circ} 4\right)$

En cualquier caso, aunque les llame la atención y les agrade verse representados en los anuncios, afirman que se fijan más en aquellos productos que les interesan e insisten en que no es necesario captar la atención con un personaje latino porque lo importante es el producto:

"Es que depende, nos identificamos más bien con lo que queremos comprar o no. Es que no nos fijamos en que tú eres un latino o español, o..." (Grupo no 1)

"Da igual, sí. Vemos un producto y queremos el producto."

(Grupo $n^{\circ}$ 1)

Pero este tipo de afirmaciones nos parece un exceso de racionalización del proceso publicitario: el mismo que les lleva a asegurar, como hemos visto, que para ellos, sería más eficaz la publicidad informativa que la persuasiva-. Es muy evidente que la presencia de personajes latinos en una campaña despierta inmediatamente su interés, crea un sentimiento favorable y potencia el recuerdo, y esta es un realidad que hemos comprobado fehacientemente en nuestra investigación cuando hemos testado campañas concretas. 


\section{El latino en las campañas generalistas}

Aunque a los inmigrantes latinos les parece muy significativa la presencia de sus personajes en las campañas de publicidad destinadas al público en general, piensan que esta es todavía muy pequeña, observación que se corresponde con la realidad.

Los sectores en cuya publicidad detectan más personajes latinos son, principalmente: 1) el bancario, mencionando en especial las hipotecas. 2) Los operadores de telefonía, recordando especialmente la marca Vodafone y sus tarifas de llamadas a bajo coste. 3) Algunas campañas sociales de instituciones del Estado que promueven la integración social -ver anuncio $n^{\circ} 3-$. 4) El sector de refrescos, mencionando las campañas de Coca-Cola. 5) El de aparatos electrónicos, mencionando la marca Sony.



Anuncio $n^{\circ}$ 3. Campaña de la Administración Central y la Unión Europea que explica las ventajas de la "cadena de la integración". 
En nuestra investigación hemos podido comprobar que, en efecto, hay una gran afinidad entre estos sectores y marcas citados por los inmigrantes y aquellos que realmente incorporan personajes latinos en su publicidad.

Esto demuestra que el recurso de mostrar personajes latinos les ha permitido a ciertos anunciantes y categorías comerciales obtener un alto nivel de notoriedad sobresaliendo ante la competencia. $Y$ debemos mencionar que en dichos sectores se encuentran aquellos anunciantes que ofrecen productos 0 servicios altamente consumidos por el inmigrante latino, como el sector financiero -envíos de dinero, créditos-, el de telefonía móvil o los servicios de las instituciones del Estado. En resumen, han utilizado caracteres latinos las marcas más próximas a estos públicos. $\mathrm{Y}$ este recurso les ha reportado resultados indudablemente positivos.

Los inmigrantes latinos piensan que la aparición de estos caracteres en las campañas publicitarias obedece al deseo del anunciante de:

- Incorporarlos como público consumidor

- Dar una visión variada, de "mosaico" cultural y étnico.

Con este segundo elemento algunos anunciantes estarían tratando de transmitir una imagen con valores de contemporaneidad, modernidad y sensibilidad social, aunque los encuestados no lo verbalicen así.

“- MODERADOR: ¿Y qué os parece la imagen que se da de las personas inmigrantes o de los latinos con esa publicidad? ¿Es buena o es mala? (...)¿Qué consiguen con eso?

- Yo creo que buscan más públicos, o sea, buscan al público latino. Es lo que yo veo, por lo menos.

- (...) Ponen... en el anuncio de Endesa, por ejemplo, ponen a cuatro chicos, se puede decir que blancos, ¿no? y a una chica, una negra. " (Grupo $\mathrm{n}^{\circ} 5$ ) 
Por otra parte creen que, en ciertas ocasiones, presentar a una persona con rasgos latinos podría rebajar el nivel de estatus de una marca. Por eso afirman que, al menos actualmente, los latinos sólo aparecerán en marcas populares:

"- Si en un anuncio de coches aparece un latino seguramente no me sentiría identificado, o el coche sería... ¿un Corsa, un Seat?

- Es que si fuera un coche muy caro, entonces ya no aparecería (un personaje latino)." (Grupo $n^{\circ} 1$ )

"Es que a veces el latino es visto por ejemplo, así... como pobre, ¿no? (...) Un latino podría vender un Renault, o si fuera una tele de alguna marca, o algo... Si saliera un latino pensarías en un producto que no puede costar muy caro..." (Grupo $n^{0} 1$ )

Así comprobamos que los propios inmigrantes asumen que su presencia aporta un elemento popular y próximo pero que resultaría contraproducente en productos de élite. Esto nos confirma que ellos mismo han asumido y practican los modelos representacionales de la sofisticación y la exclusividad propuestos e impuestos por la sociedad de consumo y las prácticas publicitarias. Pero estos estereotipos pueden cambiar con el tiempo y la actual presencia de los latinos en la publicidad puede contribuir a ello: aunque el "hombre latino" no estaba bien visto hace alguna décadas en los países anglosajones, ahora se ha puesto de moda y es considerada una figura atractiva y sexy. Pensemos en las figuras de Julio Iglesias, Antonio Banderas, Rafael Nadal...

Por otra parte, no suelen molestarse ni sentir complejo al ver determinados estereotipos de personajes latinos en campañas publicitarias. Por ejemplo, cuando la moderadora del grupo de discusión les preguntó por el anuncio de Malibú( ${ }^{(9)}$ el grupo reaccionó con naturalidad y le pareció divertido; incluso repitió espontáneamente su eslogan "Mézclate brother". Pero seguramente el 
tono de humor un tanto disparatado de esta campaña y su mensaje positivo, que apela a la calma y al disfrute, diluye sus posibles aspectos negativos.

“- 'Mézclate, brother'...

- Pero es muy gracioso. Y, a pesar del estereotipo, nos gusta saber que... que esa persona transmite alegría, transmite...

- Es gracioso.

- Transmite una gran sonrisa. Uno se siente identificado pero además le gusta." (Grupo nº 1)

De hecho, comentan que han visto anuncios que no les agradan por la representación que hacen de los latinos o de otros colectivos inmigrantes; pero cuando se les pregunta directamente si recuerdan algún anuncio que les trate mal, responden que no. $Y$ esto debemos considerarlo muy significativo porque, sin duda, un anuncio polémico por contener elementos de desprecio o burla racial no habría sido fácilmente olvidado, por leves que éstos fueran.

\section{Los elementos que caracterizan al personaje}

Hay toda una serie de elementos y de recursos que caracterizan al personaje latino aparecido en las campañas de publicidad. Nuestros encuestados han detallado los que consideran más significativos.

La principal característica son sus rasgos físicos, especialmente el color de piel, y el acento a la hora de hablar:

"Se puede decir, en general, que el latino es un poco morenito..." (Grupo n 1 )

"Solo con ver el acento ya está, ya uno sabe que es latino"

(Grupo no 4) 
Respecto al habla, recuerdan de forma espontánea haber reconocido la presencia de latinos en anuncios como el de Endesa ("Reinventar el mundo", ver anuncio $n^{\circ} 1$ ). También recuerdan que este recurso es utilizado por bancos $\mathrm{y}$ otras entidades financieras.

Respecto al habla, a algunos inmigrantes no les agrada que los personajes latinos utilicen palabras o expresiones latinoamericanas, ya que los significados varían mucho de un país de América latina a otro. Aunque es un recurso utilizado por los publicitarios para que la audiencia puede identificar rápidamente a los personajes latinos, ellos dicen preferir a los caracteres latinos que utilizan el léxico español ya, de hecho, manejan con soltura nuestros giros lingüísticos al poco tiempo de llegar.

Los personajes latinos representados ofrecen a veces, desde el punto de vista de los inmigrantes, una mezcla un tanto heterogénea, lastrada por la necesidad de reflejar a la vez varias personalidades latinas:

"Somos distintos, que no nos metan a todos en el mismo saco." (Grupo $n^{\circ} 8$ )

“- Me doy cuenta de que desconocen mucho las culturas latinas también. (...) Simplemente, que desconocen toda la variedad y mezclan." (Grupo n $\left.{ }^{\circ} 6\right)$

Además de los elementos ya mencionados, la presencia de personas latinas parece aportar a las campañas algunos elementos tonales sutiles pero muy significativos como: alegría y vitalidad; espontaneidad; interés por las relaciones familiares; vinculación con la música y el ritmo -se mencionan bailes como el reguetón, la salsa y la bachata-; mayor colorido; una forma de vestir peculiar y característica, etc.:

“- Yo creo que es lo que más se identifica porque es lo que... la salsa, la bachata... Ahí mismo uno se da cuenta de que es latino... porque aquí en España es distinto..." (Grupo no 1) 
Estos rasgos distintivos les permiten apreciar caracteres latinos también en campañas internacionales como la titulada "Real beauty" de la marca de productos cosméticos Dove (ver anuncio $n^{\circ} 4$ ):

"Aparece una mujer muy mayor y te decía 'a pesar de ello (la edad) te verás bella por dentro'. Era una mujer mayor con rasgos latinos." (Grupo n 3 )



Anuncio $n^{\circ}$ 4. Anuncio de la campaña "Real Beauty" de Dove, realizada en España por la agencia Bassat, Ogilvy \& Mather, presentando un personaje identificable como "latino". 
A veces, muy pocas, los inmigrantes latinos se quejan de que algunos anuncios les retratan de forma tópica, y mencionan la campaña de Movistar "No me cuesta" que anunciaba una tarifas especiales para latinos en un tono suavemente humorístico y romántico, y que, por otra parte, alcanzó elevados cotas de atencionalidad y recuerdo. Pero, en general, están satisfechos con cómo se les representa en la publicidad española y se identifican claramente con los caracteres latinos mostrados.

\section{La pervivencia del personaje latino}

Entramos ahora en un tema controvertido y sujeto a diferentes interpretaciones porque aún se está conformando y sólo es posible hablar de él en términos de hipótesis lejana. Aunque hemos comprobado que la incorporación de personajes latinos en los anuncios generalistas y que la creación de campañas específicas para este público reporta grandes ventajas a las marcas; aunque hemos verificado que los latinos aceptan positivamente los personajes con los que son retratados e incluso sienten emoción ante ellos, un gran número de inmigrantes latinos expresa el deseo -incluso la convicción- de que los personajes latinos deberían desaparecer y sus peculiaridades tendrían que diluirse para formar parte del carácter español, como culminación del proceso de integración social.

La opinión de algunos profesionales especializados en el tema matiza, como veremos, este punto de vista. Vamos a tratar de separar en este trabajo los hechos de las meras predicciones y las razones objetivas de las proyecciones y de los deseos. Estudiaremos brevemente las principales líneas argumentación de los inmigrantes que sustentan esta opinión, sin olvidar que entran en contradicción, al menos parcialmente, con algunos de los hechos que hemos estudiado y con sus propias opiniones manifestadas en otros momentos de las entrevistas. 
En los grupos de discusión un número significativo de entrevistados expresaron que no les gusta que se haga publicidad sólo dirigida a inmigrantes (esto ocurrió en los inmigrantes que llevaban más tiempo en España; recordemos que eran los grupos del número 5 al número 8 ). Piensan que ellos deberían -o llegarán a ser- público objetivo de las mismas campañas que se dirijan a la población española, porque se sienten iguales como consumidores y como ciudadanos, especialmente cuando ya llevan varios años viviendo en España:

“... Después de que pasa un tiempo tú te has integrado, te quedan tus raíces pero ya es distinto. Por ejemplo, Coca-Cola es Coca-Cola para ti para mí, para cualquiera. Entonces, tengo las mismas necesidades (que un español). Que luego a mí me guste más el picante, o tal o cuál, es otra cosa." (Grupo n 8)

"Nosotros somos igual que ustedes. Si hablamos de la publicidad, pues todos los producto van dirigidos a todos por igual, porque nosotros vamos a comprar lo mismo que lo que comprarán ustedes también." (Grupo n²4)

Por este motivo, preferirían verse entremezclados con los personajes no latinos, aparecer como otro personaje más dentro de la publicidad generalista. $\mathrm{Y}$ creen que, de hecho, así ocurrirá dentro de poco tiempo:

“- MODERADOR: ¿Están como muy separados... (los personajes españoles y los de otras etnias en las campañas en la que salen ambos tipos de personajes)?

- Sí, todavía, pero yo creo que en un año o dos pues ya la publicidad va a cambiar y se va hacer para todos,. para todo el mundo. Porque yo pienso que ya habrá gente que ya lleve diez años o algo así, y entonces (...) tampoco le va a gustar que estén dividiendo." (Grupo $n^{\circ} 5$ )

Pero hay una profunda contradicción entre este deseo y la pretensión que muestran al exigir disponer de más presencia en las campañas de publicidad, por la importancia numérica de su colectivo, ya que esto significaría ahondar en 
el hecho de seguir presentándolos como una etnia diferente, con los rasgos latinos típicos:

"A mí me gustaría vernos más representados porque (...) creo que uno de cada diez ciudadanos es inmigrante. Entonces, que tampoco toda la publicidad sea gente de aquí (españoles)." (Grupo $\left.n^{\circ} 8\right)$

Este punto nos parece realmente muy significativo y demuestra que, de forma intuitiva, el público comprende cómo actúan los medios de comunicación. Hace ya más de 30 años que Grant Noble ${ }^{(10)}$ demostró que, en la moderna sociedad de la información, lo que no está representado en los medios no existe en realidad para el espectador. Por ello, parece lógico que los inmigrantes quieran que los medios recojan la importancia numérica y cualitativa de su colectivo.

Pero también refleja el carácter de proyección personal que encierra inconscientemente este deseo: verse incorporado en los anuncios generalistas y fundirse en el carácter de los pueblos de nuestro país explicita sus deseos de una integración lo más rápida posible en todos los campos: social, económico y racial.

Por ello, a pesar de estas afirmaciones de "superar" la presencia de personajes latinos, consideramos que actualmente es muy útil utilizar estos personajes e incluso desarrollar campañas específicas para el público latino para un cierto tipo de empresas que ofrecen sus productos o sus servicios a los inmigrantes latinos. Recíprocamente, creemos que ello también favorece la normalización social y la integración real de este colectivo, siempre que los personajes mostrados sean tratados con respeto, como ha ocurrido, por ejemplo, con la incorporación de personas de las etnias latina o negra en la publicidad de los EEUU.

Pero, como también hemos comprobado anteriormente que los inmigrantes asumen y actúan bajo los estereotipos mayoritariamente vigentes, en algunos casos conviene que los anunciantes no realicen campañas de publicidad REDMARKA UIMA-Universidad de A Coruña - CIECID 
diferenciadas, porque la presencia de personajes españoles puede transmitir valores positivos a los productos anunciados, por ejemplo, cuando se desee connotar estatus social o económico. Cada anunciante y cada marca deben estudiar su caso concreto y medir hasta qué punto les resulta útil crear y ejecutar campañas diferenciadas.

Varios reputados especialistas coinciden con esta línea de interpretación: alguno de los expertos entrevistados recomendaron evitar campañas multiculturales forzadas. Si la marca trabaja de forma global y representa valores universales puede ser recomendable para ella no realizar una comunicación específica, pero sí integrar esta diversidad social y racial en sus mensajes, como comenta la especialista en publicidad para inmigrantes latinos Carmen Lorenzo, entrevistada para esta investigación:

"He Ilevado Coca-Cola cinco años (...) Incluso en Ecuador, la marca número uno en el mercado es Coca-cola, luego Fioravanti (...). Entonces, con Coca-Cola (los latinos) tienen esa conexión emocional, no hace falta que hagas una comunicación dirigida específicamente a ellos porque conectan. En la bobina de Coca-Cola, si has visto (los anuncios), hay (personajes) afroamericanos en muchos de ellos. El año pasado, por ejemplo, en el (anuncio) de Navidad, (...) uno de los personajes era latino."

Por eso, según ella depende del tipo de producto o servicio y de su estrategia de comunicación si resulta adecuado utilizar campañas diferenciadas o campañas generales:

"Yo creo que eso (darles un trato diferenciado en la publicidad) está muy condicionado por el producto. O sea, si un producto es absolutamente autóctono y tal, tienes que dirigirte a ellos, específicamente, con su mensaje y con su lenguaje. Si un producto es general o universal, tienes que dirigirte a la universalidad del público. Lo único que está muy bien (es) 
integrarles, como integras a cualquier otra persona, vamos, ninguna diferenciación."

Respecto a si se mantendrán los caracteres latinos de forma específica en la publicidad española o si serán absorbidos por la cultura general del país, esta es una pregunta que encontrará su respuesta en función de lo que ocurra en la propia sociedad: si -como nos parece previsible- los inmigrantes latinos conservan sus peculiaridades, disfrutarán de una presencia diferenciada en la publicidad, sobre todo si para entonces se han consolidado como consumidores activos. Así ha ocurrido en los EEUU, donde los inmigrantes latinos y sus descendientes mantienen viva su identidad y su cultura y disfrutan de medios propios y de campañas publicitarias específicas, desarrolladas por agencias especializadas.

\section{NOTAS}

(1) Ver INE, 2008.

(2) Ver Calderón, Ana (2007-08), página 4.

(3) La cifra exacta es de 961.861 personas. Ver INE, 2006.

(4) No es posible conocer datos fiables de esta inversión pues los estudio realizados en el sector, como los de Infoadex, no desglosan esta actividad

(5) Ver Ibáñez, Jesús (2003)

(6) Ver Báez y Pérez de Tudela, Juan (2007) Páginas 127-169.

(7) El grado de maduración personal de los jóvenes inmigrantes es bastante más elevado que el de los españoles para los mismos rangos de edad, por eso se eligió la edad de 23 años como cota máxima.

(8) Todos los verbatims o citas textuales están transcritas de los focus groups o grupos de discusión. Como resulta habitual en este tipo de transcripciones, 1) están recogidas de forma literal, aunque contengan incorrecciones gramaticales o palabras malsonantes; 2) las partes entre paréntesis son añadidos del transcriptor para facilitar la comprensión de la cita; 3) los puntos suspensivos entre paréntesis sustituyen palabras o frases eliminadas por 
resultar poco significativas; 4) las intervenciones del moderador están identificadas como tal; 5) al final de cada cita se detalla el grupo de discusión del que ha sido tomada.

(9) Esta campaña muestra en clave de humor a personas de raza negra, figuradamente en Jamaica, realizando algunas acciones cuestionables por su simpleza. Realizada en España por la agencia J. Walter Thompson fue distinguida con un galardón en los premios EFI.

(10) Ver Grant Noble, G. (1975).

\section{BIBLIOGRAFÍA CITADA:}

Abascal, Elena y Grande, Ildefonso (2005): Análisis de encuestas. ESIC Editorial. Madrid.

Báez y Pérez de Tudela, Juan (2007): Investigación cualitativa. ESIC Editorial. Madrid.

Calderón, Ana (2007-08): II Anuario, un referente para el país más multiétnico de la Unión Europea, en II Anuario de la Comunicación del Inmigrante en España. Etnia comunicación. Madrid.

Grant Noble, G. (1975): "Children in front of the small screen". SAGE. Beverly Hills.

Ibáñez, Jesús (2003): Más allá de la sociología. El grupo de discusión: técnica y crítica. Siglo XXI de España, Editores. Madrid.

INE (1981-2007): Encuesta de la Población Activa-EPA. Instituto Nacional de Estadística-INE. Madrid. Años de 1981 al 2008.

INE (2008): Padrón 2008. Instituto Nacional de Estadística-INE. Madrid, diciembre de 2008. 
INE (2006): Padrón 2006. Instituto Nacional de Estadística-INE. Madrid, diciembre de 2006.

\section{Para citar este artículo:}

Álvarez Ruiz, Antón (21-12-2009). QUÉ PIENSA DE LA PUBLICIDAD Y DE SUS TÉCNICAS LA COMUNIDAD DE LATINOS INMIGRANTES EN ESPAÑA.

REDMARKA - CIECID - Unidad de Investigación en Marketing Aplicado-Universidad de A Coruña, Número 3, V1, pp.3-40

ISSN $1852-2300$

URL del Documento : http://www.cienciared.com.ar/ra/doc.php?n=1163 